\title{
PROCESSOS DE SUBJETIVAÇÃO E IDENTIFICAÇÃO: IDEOLOGIA E INCONSCIENTE*
}

\author{
Belmira Magalhães** \\ Bethania Mariani***
}

Resumo: O presente ensaio tem como objetivo articular interfaces e fronteiras entre a análise do discurso, a psicanálise lacaniana e o materialismo histórico. Nosso foco é a noção de sujeito considerando o aporte teórico de Marx/Lukács relativamente à noção de ideologia e, também, o aporte teórico de Freud/Lacan com relação ao conceito de inconsciente. Na noção de sujeito, central em Análise do Discurso, concentra-se uma crítica ao idealismo e ao humanismo. É do sujeito interpelado pela ideologia, clivado pelo inconsciente e individualizado pelo Estado, que se formula uma teorização. É com relação ao sujeito enquanto posição no discurso que se constroem as análises. No artigo em tela, o conceito de subjetivação é incorporado a essa reflexão, que considera que o sujeito do discurso advém e se constitui na e pela linguagem.

Palavras-chave: Análise do Discurso. Psicanálise Lacaniana. Materialismo Histórico.

\section{INTRODUÇÃO}

A Análise do Discurso, tal como foi teorizada por Michel Pêcheux entre os anos 60 e 80, na França, e reterritorializada por Eni Orlandi no Brasil a partir da década de 80, integra em sua formalização epistemológica três campos do saber: uma teoria das formações sociais e suas transformações, uma teoria não subjetivista da enunciação e uma teoria materialista dos processos semântico-discursivos. Esses três

\footnotetext{
* Este artigo resulta de uma discussão teórica sobre questões pertinentes e atuais que vêm sendo tematizadas na linha de pesquisa Inconsciente e ideologia do Grupo de Trabalho em Análise do Discurso da ANPOLL. Parte dos resultados iniciais desta reflexão foi apresentada no Congresso Internacional da Abralin, realizado em 2009, em João Pessoa.

* Professora da Universidade Federal de Alagoas (UFAL) e Bolsista do CNPq. brcmagalhaes@gmail.com

*** Professora da Universidade Federal Fluminense (UFF) e Pesquisadora CNPq e FAPERJ. bmariani@terra.com.br.
} 
campos, segundo Pêcheux, são atravessados por uma teoria do sujeito de base lacaniana.

Neste texto, objetivamos articular interfaces e verificar limites entre a Análise do Discurso, a Psicanálise e o Materialismo Histórico, sobretudo no que diz respeito à noção de sujeito. Nossa proposta pretende um aprofundamento das noções de ideologia (Marx/Lukács) e de inconsciente (Freud/Lacan), procurando estabelecer conexões entre esses dois conceitos, que pertencem a escopos teórico-metodológicos distintos. O objetivo fundamental da pesquisa é teorizar a noção de sujeito proposta pela Análise do discurso compreendendo sua determinação pela ideologia e pelo inconsciente.

\section{A NOÇÃO DE SUJEITO E O PONTO DE VISTA DA PSICANÁLISE}

Para trabalhar esses pontos teóricos de articulação entre inconsciente e ideologia, retomo a teorização de Orlandi sobre o duplo movimento na constituição da subjetividade, considerando a presença de um outro movimento, necessário para que se realize a passagem de "Indivíduo 1" (momento de interpelação do indivíduo em sujeito) para "Indivíduo 2" (processo de individualização pelo Estado). Para Orlandi, em um primeiro momento (e, conforme a autora, não se trata aqui de uma cronologia), encontra-se justamente a interpelação do indivíduo em sujeito pela ideologia. A interpelação produz assujeitamento e isso ocorre em qualquer época histórica, em quaisquer que sejam as condições de produção, pois resulta da inscrição do sujeito no simbólico e, ao mesmo tempo, produz como resultado que esse sujeito, afetado pelo simbólico, expresse a sua subjetividade na ilusão de autonomia e de ser origem do seu dizer. "A forma-sujeito, que resulta dessa interpelação pela ideologia, é uma forma-sujeito histórica, com sua materialidade." (ORLANDI, 2002, p. 71, 72; 2001, p. 105-106)

Em um segundo momento (que não corresponde necessariamente, deve-se ressaltar, a uma temporalidade expressa em dias ou anos), ocorre o "estabelecimento (e o deslocamento) das formas de individua(liza)ção do sujeito em relação ao Estado." (ORLANDI, 2001, p. 106). Em outras palavras, ocorre uma individua(liza)ção histórica da 
forma-sujeito em função da inserção do sujeito nas relações sociais regidas pelas instituições que são reguladas pelo Estado. Do indivíduo interpelado em sujeito $\left(\mathrm{I}^{1}\right)$ resulta $\mathrm{o}$ sujeito em "sua forma individualizada concreta $\left(\mathrm{I}^{2}\right)$ ", ou seja, aquela visível e a partir da qual é possível adaptar o sujeito ao social. Como afirma a autora, "no caso do capitalismo, que é o caso presente, [é] a forma de um indivíduo livre de coerções e responsável, que deve assim responder, como sujeito jurídico (sujeito de direitos e deveres), diante do Estado e de outros homens." (ORLANDI, 2002, p. 72).

Em Orlandi, portanto, o movimento pendular de passagem de 1 para 2 supõe uma inscrição no simbólico, nas leis do simbólico, ou seja, na linguagem enquanto lugar de produção de sentidos, no qual a história e a cultura intervêm.

A inclusão da leitura lacaniana do modo como se realiza a entrada no campo da fala e da linguagem e a constituição do aparelho psíquico, ou seja, da subjetividade enquanto manifestação da divisão subjetiva, impõe a observação de um momento lógico anterior (e, mais uma vez, não se trata de uma cronologia), um momento necessário e fundamental para que se dê esse movimento de sístole proposto por Orlandi - de "indivíduo 1" para "indivíduo 2". Esse momento representa a entrada na estrutura da linguagem e ao que Lebrun chama de subjetivação (ou humanização, conforme LEBRUN, 2008). Faz-se, assim, relevante aprofundar uma discussão sobre a noção de sujeito articulada ao campo psicanalítico, tal como Pêcheux propôs quando formulou o quadro epistemológico da Análise do Discurso.

Falar implica incluir o lugar de onde se fala e a fala do Outro lugar do simbólico -, mesmo que isso não seja transparente para o sujeito. Falando, o sujeito não está em simbiose com o mundo. Ao entrar na linguagem e ao estabelecer uma distância entre as palavras e as coisas, distância necessária para constituição da subjetividade, o sujeito se vê submetido ao funcionamento de uma estrutura linguística, ou seja, encontra-se submetido a uma estrutura de linguagem, por um lado, e a sentidos já constituídos na historicidade e na memória, por outro.

Como sabemos com Saussure (1977), a língua humana é um sistema de signos, de puros valores, em que cada signo vale por sua diferença em relação aos demais do sistema. Um signo remete para outro 
signo, e nesse modo de funcionamento marca-se um distanciamento entre os signos e o que eles representam. Do ponto de vista da psicanálise lacaniana, que trazemos aqui para o campo do discursivo, importa compreender mais de perto o funcionamento do sistema dos significantes, um funcionamento marcado por uma negatividade e por uma descontinuidade: há uma distância entre um significante e outro, e nessa distância marca-se um vazio. Nossa entrada na linguagem é afetada por esse modo de funcionamento, que inclui a descontinuidade significante. Quando tomamos a palavra e falamos, nós o fazemos marcados pelo funcionamento dessa descontinuidade que inclui o vazio (o espaço entre os significantes) e traz a marca da distância entre a linguagem e o mundo. É por isso que, de acordo com Lacan, o sujeito falante, o parlêtre (LACAN, 1985, p. 188) é um sujeito dividido pelo funcionamento da linguagem, pois é "atingido por essa descontinuidade, barrado e em via de se barrar; é o que vai marcá-lo com um inconsciente.” (LEBRUN, 2008, p. 51)

Quando dizemos "eu" (o "eu" do teatro da consciência), o fazemos submetidos às leis do funcionamento estrutural da linguagem, as leis que nos permitem fazer uso de uma língua e que, simultaneamente, nos colocam frente a esse vazio, a esse hiato, a essa negatividade que habita a linguagem. É necessário que o indivíduo se inscreva, habite um sistema de linguagem para tornar-se sujeito do que diz e ser habitado pelo inconsciente. Entrar na linguagem é condição para haver e inconsciente e para estabelecer laço social. Lebrun afirma: "um sujeito não é um pleno que tem de se dizer no descontínuo da linguagem, ele é o que resulta desse descontínuo imposto pelo sistema da linguagem.” (LEBRUN, 2008, p. 51). Assim, para o autor, o que de mais importante se transmite na espécie humana, para além do caráter genético, são os significantes. E para haver a transmissão dos significantes há que haver uma aposta do sujeito.

Retomemos o que foi dito anteriormente sobre a necessidade de considerar um momento de entrada na linguagem logicamente anterior ao esquema do processo de interpelação-identificação proposto por Orlandi. Isso implica pensar na transmissão do significante, uma transmissão que se realiza no contato-convivência com os pequenos outros, representantes do grande Outro. Para haver sujeito, para haver inconsciente, é preciso passar pelos significantes desses primeiros outros, 
os quais, ocupando o lugar do Outro, transmitem as leis do simbólico. Meus significantes, os significantes que considero como "meus" estão constituídos e afetados pelo Outro: para emergir como sujeito falamos afetados pelo Outro (nesse sentido, a alteridade está em mim). O processo de subjetivação está atravessado pela materialidade significante do outro.

Ora, se até mesmo aquilo que consideramos mais íntimo está atravessado pelo Outro, como seria possível considerar a singularidade? Em artigos anteriores (MARIANI, 2005, 2006) afirmamos que há um modo singular de inscrição da estrutura do processo do significante em cada sujeito. Afirmamos que a singularidade aponta para o heterogêneo, para o descontínuo, e dizemos que pensar a singularidade, portanto, é tocar na questão da produção de diferenças subjetivas que se marcam no campo do homogêneo e contínuo (BIRMAN, 1994, p. 152). Assim sendo, vale a pena retomar o que foi dito sobre a constituição da subjetividade, considerando essa contradição entre o homogêneo e o heterogêneo causada pela singularidade enquanto produção de diferenças. A singularidade pode remeter para o que se encontraria bastante fora da ordem cultural, indo ao encontro, nesse sentido, do que é excêntrico, do exibicionismo, da perversão. Mas não é dessa diferença que se trata aqui. O que mencionamos em Mariani (2006) foi a presença da singularidade que se materializa sempre e não apenas frente à pressão de homogeneidade. Tal singularidade, enquanto diferença, se é resultado de um modo próprio de constituição do sujeito pelo processo significante, resulta também daquilo que escapa à inscrição pela via do significante, ou seja, em termos freudianos, há um algo a mais inscrito no aparelho psíquico e não absorvido no simbólico: a força das pulsões. Como afirma Birman,

[...] este algo, pólo da fundação das diferenças subjetivas, é o que permite e indica a existência de um eu sinto que não se conjuga como eu devo do imperativo categórico freudiano. [...] Esta diferença mínima entre o eu sinto e o eu devo é o que pode permitir que o sujeito constitua um estilo singular de existência, marcando de maneira radical sua diferença face a qualquer outro sujeito. (BIRMAN, 1994, p. 150, grifos nossos) 
O en devo resulta da entrada do sujeito no simbólico, com a força do assujeitamento ideológico, e estar no simbólico é estar na estrutura da linguagem, ou seja, uma estrutura com sua ordem própria, enquanto um sistema de significantes regido por oposições e diferenças.

E é importante ressaltar: as ausências contam na língua: a língua é não-toda, ou seja, fazendo eco ao pensamento lacaniano, "o todo da língua só existe constituído pelo signo ausente, pelo não dito." (PECHEUX, 2004 [1981], p. 74). Em termos lacanianos, essa característica da língua como não-toda traz um impossível: há um impossível de ser dito que insiste e retorna, causando estranhamento para o sujeito. Esse impossível irrepresentável pela língua é denominado por Lacan lalangue, lugar do não idêntico, da repetição e da não repetição ao mesmo tempo. ${ }^{1}$

Em resumo, a subjetividade - no que ela se mostra, no que se esconde, no que é repetição ou equívoco, no que se marca como diferença, no que se inscreve enquanto homogeneidade - resulta do acontecimento da linguagem ${ }^{2}$ no sujeito. Um acontecimento que tanto possibilita a singularização da diferença quanto a regulação do sujeito relativamente a uma universal adaptação do sujeito à ordem cultural e social através do mesmo simbólico que o constituiu.

Pensemos no significante "nome próprio", que hipoteticamente diria de cada um o que cada um é. Sabemos que o nome próprio pode indicar uma filiação, pode indicar algumas histórias sobre seu portador, mas nunca expressará em si um sentido único e definitivo. Não só porque ele vem do outro, mas sobretudo porque nenhum significante portará um sentido completo ou positivo sobre o ser de um sujeito. Esse significante não há, ou seja, no Outro "está sempre faltante o significante que diz o que o sujeito é.” (LEBRUN, 2008, p. 123). Em suma, como Lacan afirmou ao longo de sua obra, o Outro é faltoso, é marcado pela falta. Se é necessário o Outro para haver sujeito, e se o Outro é nãotodo, é nessa falta, nessa ausência de um significante que diga o 'quem o sujeito é' que se encontra a singularidade de cada um, a não radicalidade

\footnotetext{
1 Estamos nos valendo de algumas formulações de Leite (2000, p. 40) sobre a questão da singularidade frente ao universal, no campo do científico.

${ }^{2}$ Guimarães, partindo de outras questões, irá conceituar a enunciação, afirmando: "acontecimento no qual se dá a relação do sujeito com a língua" (GUIMARÃES, 2002, p. 8).
} 
do assujeitamento e a possibilidade de invenção e de liberdade. E é sobre esse processo de entrada na linguagem que Lebrun comenta:

É, precisamente, ao se apropriar de novo desse vazio, dessa negatividade, ao fazer sua essa falta no Outro, ao aceitar essa ausência de garantia, ao abandonar a esperança que o Outro o defina, que o sujeito pode traçar sua própria via. Da mesma maneira que é preciso aceitar deixar a borda da piscina para nadar. Logo, ele só consegue isso após ter-se de certo modo autorizado a fazer objeção ao outro. É esse trajeto que chamamos subjetivação. Um trajeto incontornável para cada sujeito, uma vez que equivale ao trajeto da humanização. (LEBRUN, 2008, p. 53)

Em suma, a inscrição na linguagem não nos possibilita perceber o vazio que a habita e que possibilita o processo de subjetivação. Falando, nos subjetivamos; ao cernirmos marcamos o vazio, pois a presença de um significante implica a ausência dos demais. Cada sujeito é fisgado, capturado na linguagem, na descontinuidade do sistema significante. Isso não se dá da mesma maneira para cada sujeito, mas afeta de modo intestino os sentidos que produzimos sobre nós mesmos, os outros, o mundo a nossa volta, nossas escolhas etc..

Nossa condição de sujeitos implica a apropriação da fala e da linguagem bem como o vazio do entre significantes, o furo, a falta de um sentido único (literal). Tomar a palavra é inscrever-se em uma rede de diferenças e é, também, entrar em redes de produção de sentidos, entrar no simbólico e tornar-se responsável - na sociedade, na cultura - por seu próprio dizer, um dizer marcado pelo eu devo e também pela falta.

Considerando que significantes e sentidos se entrelaçam na constituição e na prática discursiva do sujeito, e considerando o que foi pensado a partir de Orlandi, como foi exposto na parte inicial deste nosso artigo, propomos o seguinte esquema para sintetizar o que discutimos nesta seção:

Subjetivação

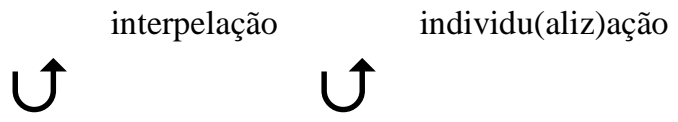




\section{A NOÇÃo DE SUJEITO E A CONTRIBUIÇÃO DO MATERIALISMO HISTÓRICO}

Para o materialismo dialético a linguagem humana faz parte do complexo do trabalho e tem sua gênese de necessidades surgidas por essa atividade vital para a manutenção da espécie humana. Como diz Lukács (1997, p. 34)

É sem dúvida possível deduzir geneticamente a linguagem e o pensamento conceitual a partir do trabalho, uma vez que a execução do processo do trabalho põe ao sujeito que trabalha exigências que só podem ser satisfeitas reestruturando ao mesmo tempo quanto à linguagem e ao pensamento conceitual as faculdades e possibilidades psicofísicas presentes até aquele momento, ao passo que a linguagem e o pensamento conceitual não podem ser entendidos nem em nível ontológico nem em si mesmos se não se pressupõe a existência de exigências nascidas do trabalho e nem muito menos com condições que fazem surgir o processo de trabalho.

No entanto, é imprescindível perceber que haverá sempre reciprocidade entre as necessidades do trabalho e a efetivação linguagem, que se transformam simultaneamente, isto é:

É obviamente indiscutível que, tendo a linguagem e o pensamento conceitual surgidos para as necessidades do trabalho, seu desenvolvimento se apresenta como uma ininterrupta e inalienável ação recíproca e o fato de que o trabalho continue a ser o momento predominante não só não suprime estas interações, mas, ao contrário, as reforça e as intensifica. Disto se segue necessariamente que no interior desse complexo o trabalho influi continuamente sobre a linguagem e o pensamento conceptual e vice-versa. (LUKÁCS, 1997, p. 34)

O que leva à conclusão, para o materialismo histórico-dialético, de que o entendimento da práxis discursiva requer a compreensão da 
realidade objetiva com ênfase nas relações de produção tão amplamente salientadas por Pêcheux, em Semântica e discurso (PÊCHEUX, 1988 [1975], p. 125), ao considerar o objeto de seu estudo como "uma abordagem teórica materialista do funcionamento das representações e do "pensamento' nos processos discursivos". O autor ainda assinala o grande erro dos estudiosos do discurso que não levam em conta "o termo e o conceito de contradição, bem como o de luta de classes." (PÊCHEUX, 1988 [1975], p. 132).

Nesse sentido, pode-se afirmar que a linguagem possibilita e potencializa a expressão e a comunicação dos distanciamentos do real, que se originam nas relações do trabalho, possibilitando, então, o processo de universalização para sociabilidade daquela práxis realizada, sendo essa a gênese do caráter social do sentido, pois "o sentido é socialmente construído pelo homem, para si e para os seus semelhantes." (LUKÁCS, 1997, p. 70).

Tendo por base o que temos discutido até agora, fica evidenciado o assujeitamento do sujeito às determinações sociais, que têm as relações de produção de cada sociabilidade como fundantes. No entanto, a compreensão desse aspecto dessa maneira tornaria o sujeito um epifenômeno das relações sociais sem nenhuma interferência da subjetividade ${ }^{3}$. Para que isso não ocorra é necessário fazer com que as categorias de determinação e liberdade estejam sempre relacionadas.

Para o materialismo histórico-dialético, a liberdade do sujeito está relacionada com a capacidade que este adquire a partir do salto ontológico que o separa da processualidade dos seres orgânicos de pensar por objetivo, dando respostas às necessidades cotidianas de cada sociabilidade e tempo histórico. Liberdade será entendida, então, "como aquele ato de consciência que dá origem ao novo ser posto por ele (ato). Liberdade como momento da realidade, seu funcionamento está, em primeiro lugar, numa decisão concreta entre diversas possibilidades concretas" (LUKÁCS, 1997, p. 74).

Percebe-se que o sujeito está sempre orientando sua ação por um "querer" transformar a realidade, sendo que todas as opções dessa transformação estão postas, mesmo aquela que tenta impedir qualquer

${ }^{3}$ Essa á a compreensão do materialismo mecanicista, que tira do sujeito qualquer posição de importância na realização da realidade social. Ver em Marx (1965) as teses sobre Feuerbach. 
mudança, o que significa que a realidade é sempre o motor de qualquer possibilidade de exercício da liberdade, mesmo quando se tem a abstração mais ampla ${ }^{4}$ e que a liberdade está sempre sujeita ao determinismo.

Nesse sentido, Lukács (1997, p. 74) afirma que "até que a intenção de transformar a realidade tenha sido demonstrada, os estados de consciência - as reflexões, os projetos, os desejos etc. - não têm nenhuma relação real com o problema da liberdade".

O conceito de ideologia, tão contraditório e, ao mesmo tempo, tão necessário para o entendimento dos processos sociais e individuais, tem, a partir do materialismo histórico-dialético, seu centro conceitual na noção de práxis.

A ideologia faz parte das teleologias secundárias e tem como objetivo conduzir as práticas humanas. Para Lukács (1997, p. II), "as formas ideológicas são instrumentos pelos quais são conscientizados e enfrentados os problemas que preenchem (a) cotidianidade." Nessa perspectiva, a ideologia percorre todas as ações humanas, não estando presente apenas em momentos de crise e tendo como pressuposto a resolução de problemas: "a ideologia é acima de tudo aquela forma de elaboração ideal da realidade que serve para tornar a prática social dos homens consciente e operativa.” (LUKÁCS, 1997, p. II).

Nesse sentido, o caráter histórico/social da ideologia tem que ser enfatizado, pois na medida em que se transformam as sociedades também se transformam as formas de atuação das subjetividades entre si. Como afirma Magalhães (2001, p. 34-35):

Sem a interferência da subjetividade é impossível qualquer escolha entre as alternativas existentes na objetividade, que funcionaria apenas com sua lógica interna ou ao sabor do acaso ${ }^{5}$. $\mathrm{Na}$ verdade, é o surgimento da subjetividade que instaura o ser social; e a história do gênero humano é a história da intervenção da subjetividade na objetividade. É nessa relação que se consubstancia a força do sujeito. O limite da subjetividade é dado

\footnotetext{
${ }^{4}$ Dessa forma se explicam até as abstrações das expressões artísticas. Ver Magalhães, 2001.

${ }^{5}$ A legalidade do mundo inorgânico e do orgânico, que não permite a criação do novo.
} 
pela objetividade que não permite qualquer tipo de intervenção, mas apenas aquelas que condizem com sua legalidade.

Percebe-se, assim, que a liberdade não é um sonho de independência dos liames naturais e sociais, mas está diretamente associada ao conhecimento das leis dessas instâncias e na possibilidade de controlá-las. Embora o conhecimento necessite de objetividade para se tornar viável, ele está sempre associado a uma orientação que não se prende apenas aos nexos do objeto a ser transformado, mas também aos interesses da sociedade; em sociedades divididas em classes sociais essa orientação passará inevitavelmente pela luta de classes. Por esse motivo, para o materialismo histórico-dialético, a única forma de se ter um critério sobre a verdade do conhecimento só pode ser buscado na própria realidade. Pois, assim como, ao fazer de uma tora um berço de criança (teleologia primária para transformar a natureza), tem-se que levar em consideração as qualidades do material a ser empregado para que se tenha êxito no intento, há necessidade de avaliar as relações de classes e ideológicas e a estrutura da língua, que inclui os equívocos, para que o discurso alcance os objetivos pretendidos. Fica evidenciado que a avaliação do sucesso só pode ser realizada pós-festum, mesmo quando se consegue ter o domínio sobre o objeto.

Com essas afirmações aparece como central a imbricação entre determinismo e liberdade; do ponto de vista do sujeito do discurso diremos que o assujeitamento e a autoria possuem um entrelaçamento que não se desfaz nunca. "Sem dúvida continua a subsistir a indissolúvel coexistência entre o determinismo por parte da realidade social e a liberdade da decisão alternativa" (LUKÁCS, 1997, p. 84). No caso particular do discurso, essa lógica não se altera. O discurso é a objetividade feita subjetividade, através de um pôr social feito de linguagem.

Essa é a grande marca da originalidade do pensamento de Marx: a conversão da subjetividade em objetividade. Há um trânsito dialético entre objetividade e subjetividade, que não se confundem, mas que estão presentes na realidade. "Para Marx o mundo real, objetivo, concreto, sensível, efetivo, tem a forma da subjetividade" (CHASIN, 1999, p. 104). 
O que queremos enfatizar com essa discussão é a importância dada à subjetividade pelo materialismo histórico-dialético. Não estamos falando de um sujeito idealista que pode tudo e comanda o mundo apenas através de seus desejos e vontade, mas de um sujeito determinado por uma objetividade, que introduz as marcas das relações sociais através da ideologia que, por sua vez, desencadeia a inculcação inconsciente em cada indivíduo.

Como Lukács (1997) afirma, a cada tempo e espaço social cabe uma individualidade que reage às determinações a partir das possibilidades da própria objetividade, e acrescentaríamos, a partir de Freud e Lacan, da forma como foi elaborado individualmente pelo seu consciente/inconsciente, reagindo diferentemente, dependendo das formações inconscientes de cada indivíduo. Esse sujeito determinado pelas relações de classe de seu tempo, interpelado pela ideologia e atravessado pelo inconsciente que Pêcheux traz para os estudos linguísticos, isto é, uma subjetividade objetivada passível de ser compreendida cientificamente.

\section{O SUJEITO NA TEORIA DO DISCURSO}

Um aspecto central da teoria da análise do discurso no que diz respeito à noção de sujeito, como já salientado, é a crítica à leitura idealista, que pressupõe uma existência a priori do sujeito. O engano idealista (PÊCHEUX, 1988 [1975], p. 153, 154) está vinculado à ilusão do teatro da consciência, marcado por um eu: "eu penso, eu falo, eu sou, eu vejo". Esta centralidade do $e \boldsymbol{U}$, um $\boldsymbol{e}$ concebido como portador de uma consciência e de uma autonomia manifestada em intenções e escolhas, aponta para a ideia de uma identidade própria, una e estável. E dessa identidade estável, espera-se uma coerência em atitudes, posicionamentos e ações nas diferentes esferas da prática social.

Para a Análise do Discurso, o sujeito é constituído pelo esquecimento daquilo que o determina, ou seja, não se dá conta de sua constituição por um processo do significante no funcionamento da linguagem na interpelação ideológica e na identificação imaginária a determinados sentidos. Desse ponto de vista, falar do sujeito é falar de efeito de linguagem; sujeito enquanto um ser de linguagem que foi falado 
antes de falar, que traz marcas do discurso do Outro, o que implica considerar que o sujeito não é origem do dizer nem controla tudo o que diz. O Outro, aqui grafado com maiúscula, designa o que Lacan, em boa parte de sua obra, recorta da linguagem verbal enquanto tesouro de significantes, como representação de uma cena anterior, exterior e permeada pelo simbólico. É uma categoria que aponta para diferentes elementos de linguagem que marcam a enunciação do sujeito do inconsciente no espaço deixado vazio entre dois significantes. As manifestações do inconsciente marcam a divisão subjetiva e o fato de que não é possível falar do sujeito como uma unidade de uma interioridade.

$\mathrm{Na}$ teoria do discurso, mais especificamente em Semântica e discurso (1988 [1975], p. 133), Pêcheux retoma de Lacan as afirmações "o inconsciente é o discurso do Outro" e "o sujeito só é sujeito por seu assujeitamento ao campo do Outro, o sujeito provém de seu assujeitamento sincrônico a esse campo do outro" (PÊCHEUX, 1988 [1975], p. 183), para justamente frisar que "o recalque inconsciente e o assujeitamento ideológico estão materialmente ligados, sem estar confundidos, no interior do que se poderia designar como o processo do Significante na interpelação e na identificação" (PÊCHEUX, 1988 [1975], p. 133-134, grifos em negrito nossos). Em outro momento de sua obra, no artigo Só há causa daquilo que falha ou o inverno político francês: início de uma retificação (PÊCHEUX, 1988 [1975], p. 293 et seq.), como o próprio título indica, Pêcheux, em nova releitura sobre a Tríplice Aliança (Linguística, Marxismo e Psicanálise), retoma de Lacan a virulência do conceito de inconsciente como aquilo que desacomoda a ilusão da literalidade dos sentidos e a ilusão de autonomia do sujeito. Ou seja, face às manifestações da instância do inconsciente, a trilogia sujeito-centrosentido do teatro da consciência se depara com o non-sens da divisão subjetiva. Nesse artigo, sendo mais pontual e incluindo ainda mais fortemente o contexto teórico em que a Psicanálise e o Materialismo Histórico podem ser articulados, Pêcheux dirá que "a ordem do inconsciente não coincide com a da ideologia, o recalque não se identifica nem com o assujeitamento nem com a repressão, mas isso não significa que a ideologia deva ser pensada sem referência ao registro inconsciente." (PÊCHEUX, 1988 [1975], p. 301, grifos nossos). Essa 
tripla negação, outra forma de fazer uma mise an point sobre o sujeito, retoma e reformula o lugar do sujeito na teoria do discurso.

Para o analista de discurso, as marcas de subjetividade inscritas no dizer assinalam, simultaneamente, mas sem estarem misturadas ou confundidas, traços do registro inconsciente, da identificação (ou não) a uma determinada formação discursiva e, também, traços do assujeitamento ideológico. O sujeito, no entanto, alienado no seu dizer, não percebe (em) tais marcas, não se percebe constituído pelo Outro, por essa rede de significantes que o constituiu. Ou seja, nós nos pensamos espontaneamente como origem de nossos pensamentos, atos e palavras.

Essas afirmações da teoria da Análise do Discurso reterritorializam o que a Psicanálise lacaniana e também o Materialismo Histórico postulam: estamos aprisionados no campo da linguagem e às evidências que nele se constituem. É propondo uma discussão da constituição histórica dessas evidências, teorizando sobre a imbricação entre inconsciente e ideologia na materialidade da língua, que Pêcheux constitui o terreno da teoria do discurso: a evidência de que somos sempre já-sujeitos e a evidência da transparência e literalidade dos sentidos, ambas apagando, parcialmente, o funcionamento do processo significante na constituição da subjetividade.

E aqui o entremeio com a Psicanálise e com o Materialismo Histórico se fazem presentes na teoria da Análise do Discurso, posto que o sem-sentido provocado pelo inconsciente e a contradição presente nos rituais da interpelação ideológica sempre fraturam e colocam à mostra o teatro da consciência. Em suma, há um ponto de impossível - marcado na ordem da língua pelo ato falho, pelo chiste e pelas contradições - que torna visível o fato de que não há um assujeitamento total, uma alienação completa do sujeito.

Como diz Lukács (1997), a ideologia tem como função efetivar, na práxis, as ideias necessárias ao desenvolvimento social (determinadas pelas relações de produção). Para isso precisa, desde o início do desenvolvimento do ser individual, se utilizar da instituição familiar, qualquer que seja o tipo dessa instituição, que depende do momento histórico e de cada sociabilidade, como a primeira e, nesse sentido, aquela que marcará o restante da vida dos indivíduos. Marcas que 
definirão a base da individualidade em geral e de cada um. A forma como cada indivíduo sofrerá esse processo de ser dito pelo Outro e a forma como se estruturará sua imagem a partir desses dizeres (LACAN, 1992) serão fundantes para o psiquismo de cada indivíduo (FREUD, 1976).

Antes do nascimento, os seres sociais são submetidos à ação ideológica. Normalmente, nas sociedades modernas capitalistas, essa primeira abordagem é feita através dos membros da família nuclear. Inculcações sobre o lugar de homens e mulheres na sociedade são ditadas ao indivíduo pelas escolhas que a família realiza de roupas, quartos, nomes etc., assim como as expectativas, esperanças, objetivos que os adultos têm em relação ao novo ser. Tudo isso participará do inconsciente e vai sendo ressignificado no decorrer da história de vida de cada indivíduo. É importante frisar que esse processo, embora oriundo de relações sociais que afetam todos os seres sociais, é recebido de forma singular, o que faz com que cada indivíduo elabore de forma diferente a mesma práxis, tornando diferenciada a subordinação às práticas ideológicas.

Assim, estamos também juntos com Pêcheux (1997) ao afirmar que a identificação discursiva se dá pelas filiações sócio-históricas (formação ideológica e formação discursiva), admitindo uma agitação no interior destas. A práxis torna possível sempre, de forma consciente e inconsciente, o deslocamento do sujeito. Haverá sempre a possibilidade do desvio, do equívoco (ideologia/inconsciente).

Como vimos, a transmissão do significante vem do outro e nessa transmissão tanto se efetiva a possibilidade de tornar-se sujeito... falante quanto faltante. Se podemos supor que a transmissão da falta se dá pelo contato com os pequenos outros, não podemos descartar a sociedade, a cultura e a história, enfim, o meio no qual o sujeito se insere. Esse meio sócio-histórico produz efeitos no modo como a transmissão se realiza. Em outras palavras, o processo de subjetivação (ou de humanização, conforme a proposta de Lebrun já mencionada) se inscreve necessariamente na ordem histórico-social, recebendo da ordem social e cultural os rituais que administram modos de ser e de estar em dada formação social. Nesses rituais - "encenação, teatralização, ficção", nos termos de Legendre (2001) - o subjetivo e o social se interpenetram e se marcam na linguagem. Mas, como "não há ritual sem falhas" 
(PÊCHEUX, 1988 [1975], p. 301), desestruturações e reestruturações estão sempre se manifestando na ordem do discurso, apontando, justamente, para a falta e para a impossibilidade de um assujeitamento completo e sem falhas.

Nesse sentido, o sujeito determinado socialmente e o sujeito do inconsciente, efeito de um significante para outro significante (LACAN, 1985), têm sempre um lugar de não-filiação, dado também pelas possibilidades da própria realidade, seja ela tomada no nível macro, seja no referido, como faz Pêcheux (retomando Jean-Claude Milner, 1987), à língua, quando esta incorpora a poesia: “- nada da poesia é estranho à língua. - nenhuma língua pode ser pensada completamente se aí não se integra a possibilidade de sua poesia" (PÊCHEUX, 1990, p. 51), isto é, a possibilidade da transgressão da norma, da criação do novo.

Sintetizando, o discurso não é, pois, uma construção de um sujeito independente das relações sociais e do condicionamento inconsciente, mas, ao contrário, o fazer discursivo é uma práxis humana que só pode ser compreendida a partir do entendimento das contradições sociais que possibilitaram sua objetivação e de como cada indivíduo processa através do seu psiquismo essas determinações.

\section{REFERÊNCIAS}

BIRMAN, J. Psicanálise, ciência e cultura. Rio de Janeiro: Jorge Zahar Editor, 1994.

CHASIN, J. Crítica ao liberalismo, Maceió, 1999, mimeo.

FREUD, S. Obras escolhidas. Edição Standard Brasileira das obras psicológicas completas. Volume XIX. Rio de Janeiro: Imago, 1976.

GUIMARÃES, E. Semântica do acontecimento. Campinas: Pontes, 2002.

LACAN, J. O Seminário: o eu na teoria de Freud e na técnica da psicanálise. Rio de Janeiro: Zahar, 1992.

O Seminário: livro 20: mais, ainda. Rio de Janeiro: Zahar, 1985.

LEBRUN, J.-P. A perversão comum; viver juntos sem outro. Rio de Janeiro: Companhia de Freud, 2008. 
LEGENDRE, P. De la société comme texte. Linéaments d'une anthropologie dogmatique. Paris: Fayard, 2001.

LEITE, N. V. Sobre a singularidade. Cadernos de Estudos Lingüísticos - A singularidade como questão, Campinas, n. 38, p. 39-49, 2000.

LUKÁCS, G. O trabalho. Tradução de Ivo Tonet. Maceió: 1997. Mimeo.

MARIANI, B. Imaginário linguístico: análise do discurso e psicanálise. Correio da Associação Psicanalítica de Porto Alegre (APPOA), Porto Alegre, Ano XII, n. 132, jan. 2005.

. Sentidos de subjetividade: imprensa e psicanálise. Polifonia. Revista do Programa de Pós-graduação em Estudos de Linguagem, Cuiabá, v. 12, n. 1, p. 21-45, 2006.

MAGALHÃES, B. Os desejos de sinhá Vitória. Curitiba, HDlivros, 2001.

MARX, K. A ideologia alemã. São Paulo: Zahar, 1965.

MILNER, J.-C. O amor da língua. Trad. Ângela C. Jesuíno. Porto Alegre: Artes Médicas, 1987.

ORLANDI, E. Língua e conhecimento lingüístico; para uma História das Idéias no Brasil. São Paulo: Cortez Editora, 2002.

Pontes, 2001.

Discurso e texto: formulação e circulação dos sentidos. Campinas:

PÊCHEUX, M. Semântica e discurso: uma crítica à afirmação do óbvio.

Campinas: Editora da Unicamp, 1988 [1975].

O discurso: estrutura ou acontecimento. Campinas, Pontes, 1990 [1988].

A língua inatingível: o discurso na história da lingüística. Campinas, Pontes, 2004 [1981].

SAUSSURE, F. de. Curso de lingüística geral. São Paulo: Cultrix, 1977.

Recebido em 08/09/09. Aprovado em 10/08/10. 
Title: Subjectification and identification processes: ideology and the unconscious Author: Belmira Magalhães; Bethania Mariani

Abstract: The present essay aims at articulating interfaces and frontiers between Discourse Analysis, Lacanian psychoanalysis and Historical Materialism. The focus bere is the notion of the subject, taking into account the theoretical contributions by Marx/Lukács relative to the notion of ideology, and also the contributions by Freud/Lacan in relation to the notion of the unconscious. In the notion of the subject, central for Discourse Analysis, a critique is concentrated on idealism and bumanism. It is from that subject interpellated by ideology, split by the unconscious and individualized by the State that a theorization is built. It is in relation to that subject understood as a position within discourse that one builds the analyses. Here the concept of subjectivation is incorporated to this reflection, which considers that the subject of discourse comes from and is constituted within and by language.

Keywords: Discourse Analysis. Lacanian Psychoanalysis. Historical Materialism. 